\title{
Repair and rehabilitation of corroded HDPE100 pipe using a new hybrid composite
}

\author{
A. Regad, D. Benzerga, H. Berrekia \\ LSCMI, University of Sciences and Technology of Oran, Mechanical Department, B.P. 1505, 31000 Oran, Algeria \\ abdelmalekregad@yahoo.fr,djeb_benz@yahoo.fr,babib.doctorat@hotmail.com
}

Haddi Abdelkader

Univ. Artois, ULR 4515, Laboratoire de Génie Civil et géo-Environnement (LGCgE), Béthune, F-62400, France

abdelkader.haddi@univ-artois.fr

Chekhar Nourredine

Production Director - PTI Polymer Transformation Innovation, Oran, Algeria

nourdine.chakb@gmail.com

ABSTRACT. The good management of drinking water begins with a supply network, with a low rate of leakage. Currently, the pipes used in the water transport system are mainly made of polymeric materials, such as HDPE. The corrosion degradation of this type of pipe has received a lot of attention from the drinking water supply companies. It is therefore important to understand the effect of pressure on an HDPE pipe with a surface defect. To answer this problem, we will first study the mechanical behavior at failure of HDPE pipes in the presence of a surface defect using a finite element method. For the rehabilitation of pipe in presence of surface defect, we try to use a new composite. This new laminated composite is reinforced with a natural organic load. It is obtained from a laminated composite woven by incorporating a natural non-polluting organic load (granulates of date cores) which becomes hybrid composite. The new economical hybrid composite material is made of an organic matrix containing methyl methacrylate, a woven reinforcement including a reinforcing glass fiber and a fabric perlon having an absorbing role. The textile reinforcement made up of several folds reinforcing laid out according to the orientations (90, 45, and 0). A numerical simulation with the ANSYS Workbench software is carried out to study the behavior of the HDPE pipe with surface defect and with defect repaired by the new hybrid composite material in the form of rings to consolidate the cracked area of the tube. The numerical results will allow us to decide on a real practical use of the new hybrid composite. 
KEYwORDS. Rehabilitation; Pipe HDPE; Superficial defect; Finite Element Method; New hybrid composite.

\section{INTRODUCTION}

oday, the deterioration of underground drinking water supply pipes has become a growing concern of industrial and environmental sectors. The global water crisis and the scarcity of water resources require good management of this precious resource. Good management begins with a reliable drinking water supply system with a low leakage rate. Leaks caused by the rupture of pipes, a fairly common phenomenon in urban areas, are initiated by a corrosion or other defects. The severity of these phenomena depends on several parameters including the nature of the material of the pipes. Polymeric materials, such as HDPE, occupy a large part of the water transport market, thanks to their multiple qualities (reduced cost, ease of installation, flexibility). In fact, the annual growth in the number of accidents occurring in water supply networks (aqueducts) and the huge rehabilitation budgets that result from it are at the origin of the search for innovative techniques in terms of assessment and prevention against corrosion damage. Currently, the pipes used in the water transport system are mainly made of polymeric materials, such as HDPE. The corrosion degradation of this type of pipe has received a great deal of attention from drinking water supply companies and also from producers of these materials. The soil where these pipes are located is a favorable environment which accentuates all types of defects despite the protection of these pipes. The unfavorable environment and the damage in the pipes led to explore different repair options for functional maintenances such as reinforcements in composite materials. The concern of pipeline network managers is to see the breaks that represent a potential threat because of their economic and social transformations [1-5]. In addition, the repair of faults and premature replacement of pipes leads to significant financial losses [6-10]. Therefore, the evaluation of the residual strength of pipes with defects should be as accurate as possible and based on confirmed experimental and numerical methods [11-18]. The objective of our work is to assess cracked HDPE pipes considering the crack size effect on the burst pressure. For this purpose, a finite element model is developed in ANSYS software. The model is validated with experimental data [19]. The maximum service pressure that an HDPE pipe with surface defect could be computed from the numerical model and used for comparison. Then, we studied the behavior of the tube with the new hybrid composite material. The hybrid composite that served as a ring strengthening on the weakened area by the corrosion. The numerical results obtained are important for practical use of the new hybrid composite for rehabilitating drinking water supply pipes in HDPE.

\section{NUMERICAL MODELING}

o model the pipeline we used the ANSYS Workbench 2020R1 software. A model has been developed that simulates the behavior of a HDPE pipe following an increase in internal pressure while taking into account the presence of a longitudinal crack in its outer wall. Given the symmetry of the HDPE 100 tube, we modeled a half cylinder. The dimensions of the structure are: length, radius and thickness. Thus we were able to model the surface defect of the HDPE tube by taking into account the geometry of the defect, the boundary conditions and the mesh [20].

For the simulation, we used the experimental results presented in [19]. Initially, we modeled a pipe in PEHD100 without defect presenting the same characteristics as those presented in [19] and we calculated the rupture pressure which corresponds to the value of the Von Mises stress when this one reaches the tensile strength of the material. Then we modeled a tube of the same grade with a parabolic defect with variable lengths and depths and calculated for each type of defect the corresponding rupture pressure. Only a tube with a diameter of $125 \mathrm{~mm}$ and a thickness of $12 \mathrm{~mm}$ was simulated. The effect of the depth of the defect was studied by varying the depth "a" for each specimen. The length of the defect "c" varies as a function of "a". The width of the defect remains very small compared to the other dimensions (see Fig. 1). The results obtained are compared with the experimental results.

The geometry studied is an HDPE 100 tube with an outside diameter of $125 \mathrm{~mm}$ and a thickness of $12 \mathrm{~mm}$ containing a longitudinal defect on its outside surface of length c and depth a. Different sizes of the defect are treated (see Tab. 1)

For the model with superficial defect (crack), a cavity was created which represents the defect on the tube. To do this, we create a parabolic half-surface at the end of the tube. The volume of the defect is obtained by a rotation of $90^{\circ}$ around the upper line of the tube wall. This volume is subtracted from the volume of the original tube without defect, which gives 
us a quarter-tube with a quarter-defect [21] (see Fig. 2).

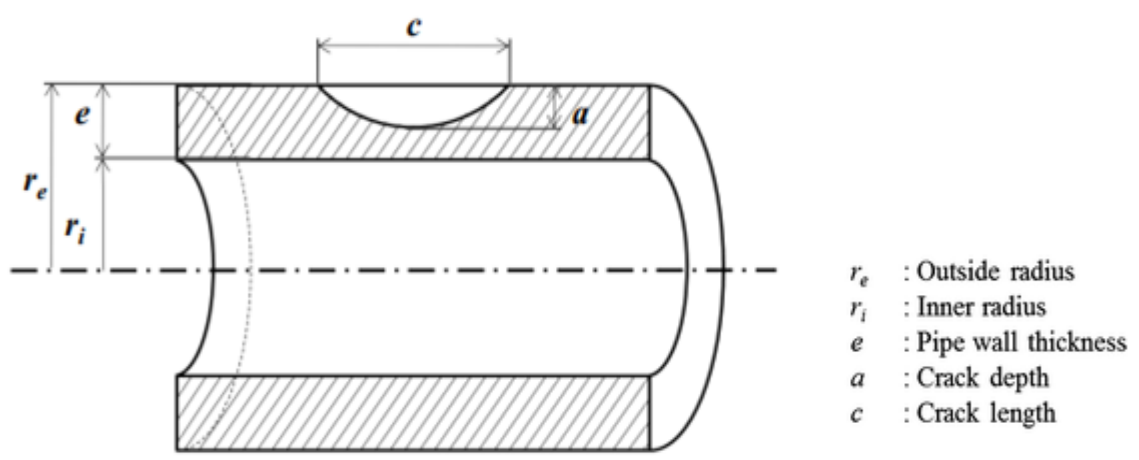

Figure 1: Geometry of the defect

\begin{tabular}{ccc}
\hline $\mathbf{a}(\mathbf{m m})$ & $\mathbf{a} / \mathbf{e}$ & $\mathbf{c}(\mathbf{m m})$ \\
2 & 0.167 & 25 \\
4 & 0.333 & 34.87 \\
6 & 0.5 & 42.14 \\
8 & 0.667 & 48 \\
10 & 0.833 & 52.91 \\
\hline
\end{tabular}

Table 1: Geometric characteristics of the surface defects

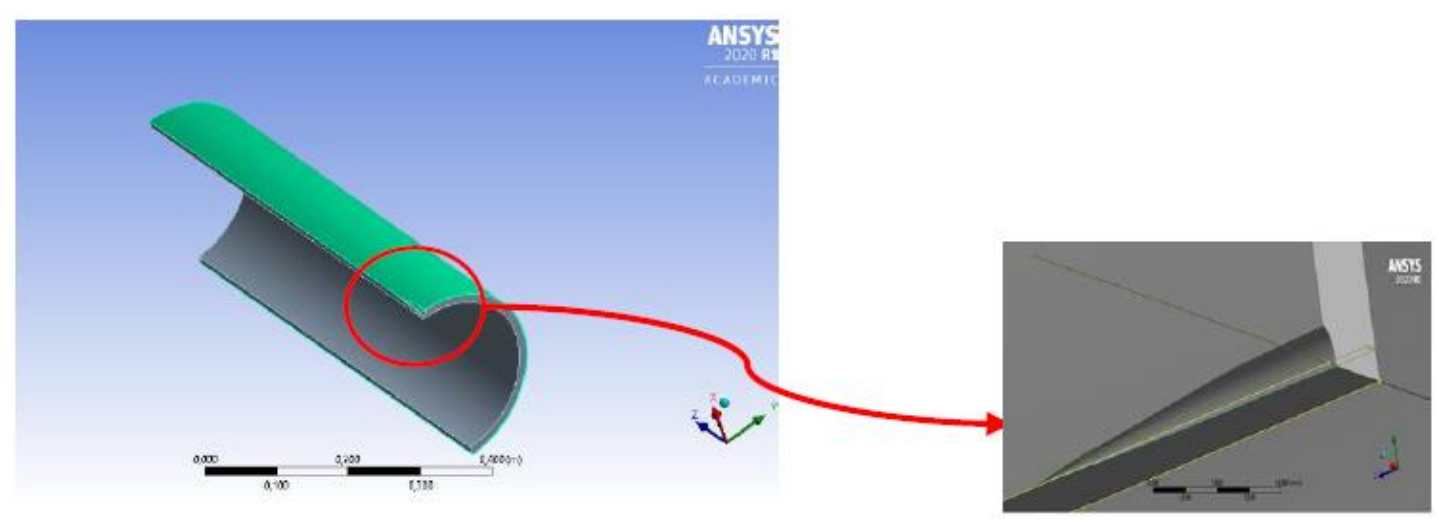

Figure 2: Pipe with elliptical defect

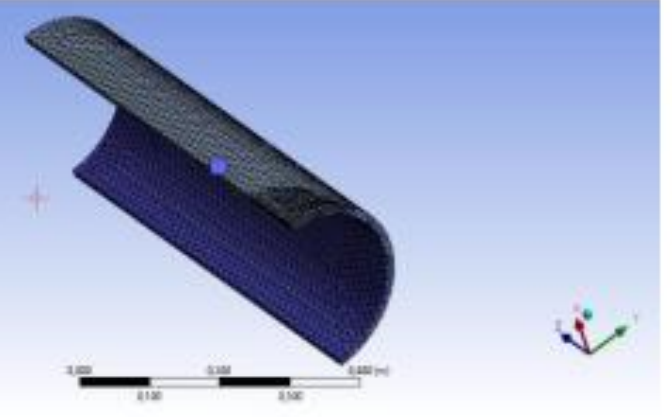

a

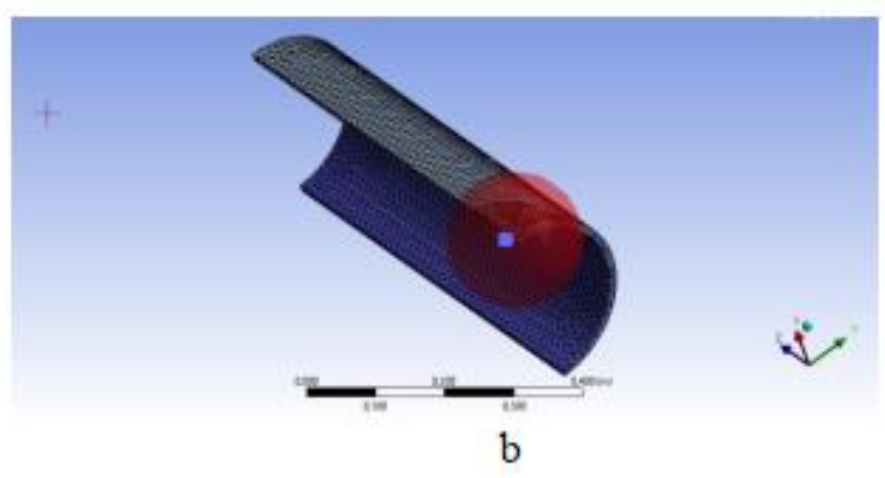

Figure 3: HDPE 100 tube meshing. 


\section{Pressure : 10 bars}

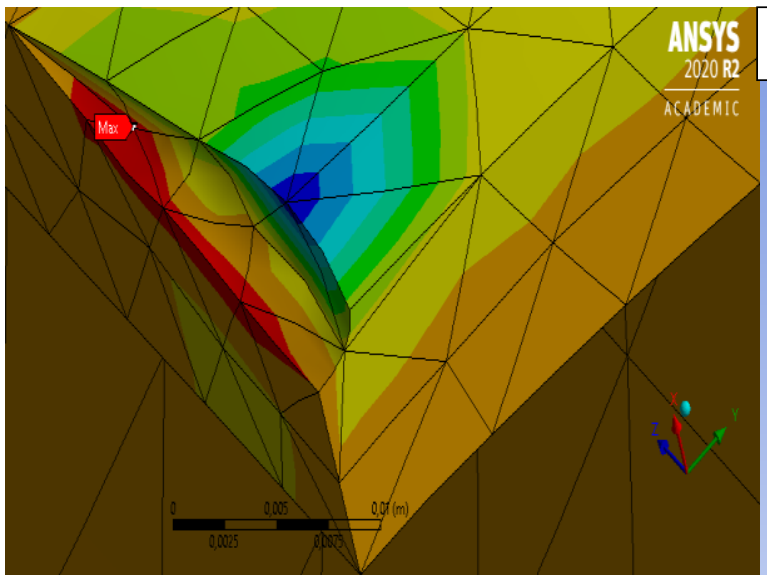

Von Mises stress

\section{1,4394e 7 Max}

$1,3141 \mathrm{e} 7$

$1,1888 \mathrm{e} 7$

$1,0635 \mathrm{e} 7$

$9,382 \mathrm{e} 6$

$8,129 \mathrm{e} 6$

$6,8759 \mathrm{e} 6$

$5,6228 \mathrm{e} 6$

$4,3698 \mathrm{e} 6$

3,1167e6 Min

\section{Pressure : 20 bars}

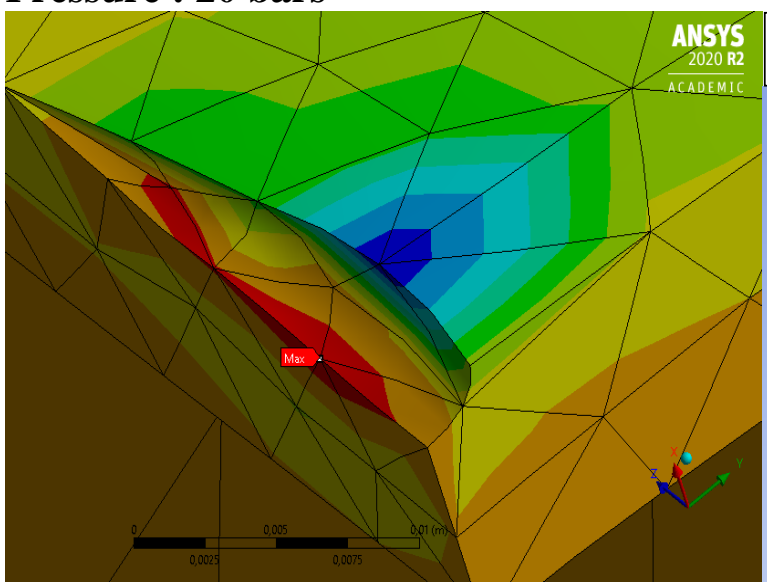

\section{Von Mises stress \\ 2,2931e 7 Max \\ $2,1033 \mathrm{e} 7$ \\ $1,9136 \mathrm{e} 7$ \\ $1,7239 \mathrm{e} 7$ \\ $1,5341 \mathrm{e} 7$ \\ $1,3444 \mathrm{e} 7$ \\ $1,1546 \mathrm{e} 7$ \\ $9,6489 \mathrm{e} 6$ \\ 7,7515 e 6 \\ 5,8541e6 Min}

\section{Pressure : 25 bars}

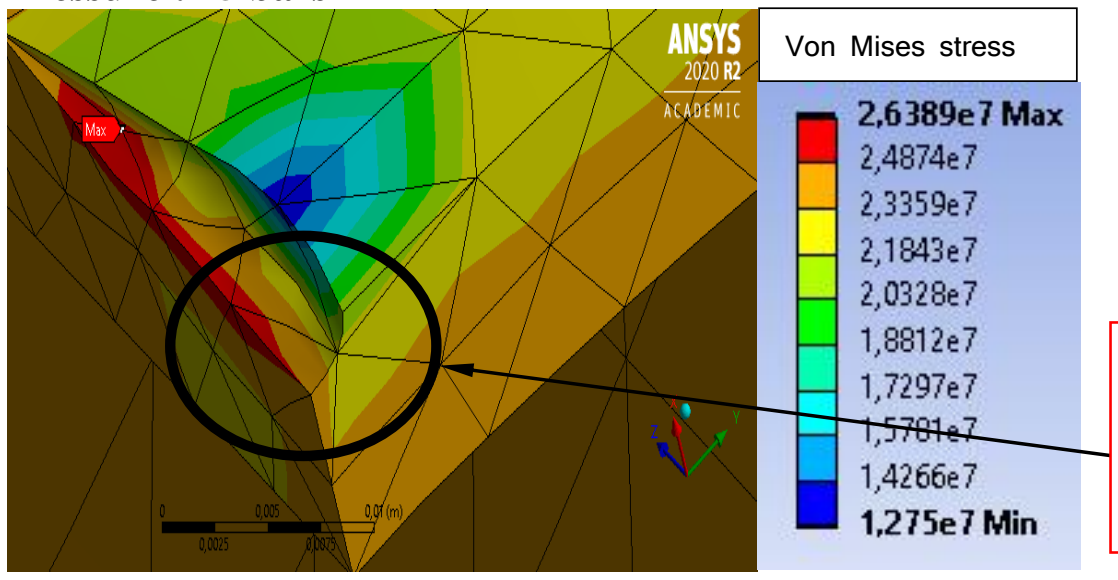

\section{Increased pressure}

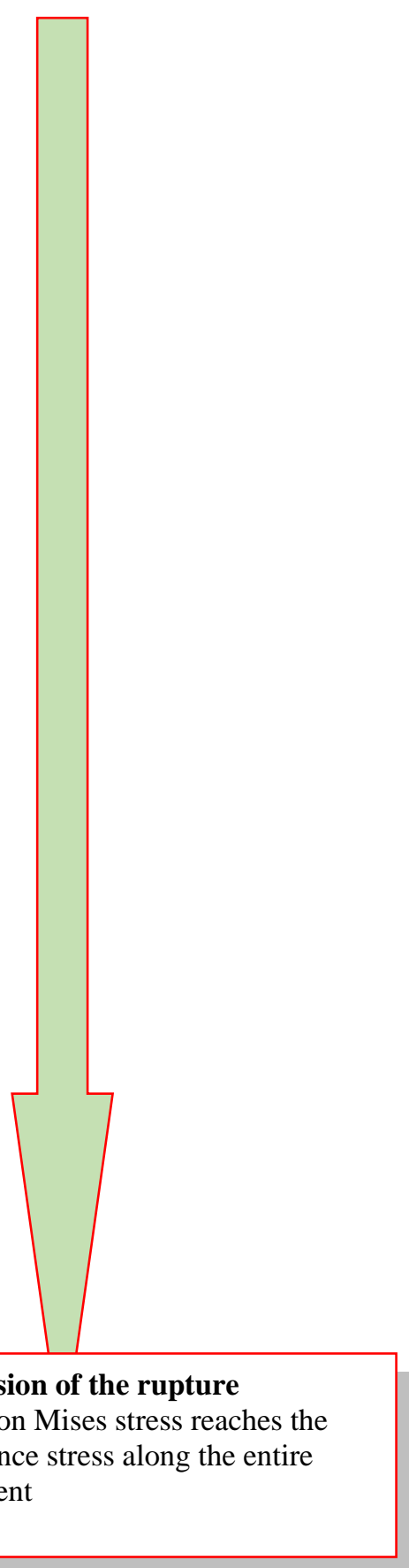

Figure 4: The variation of the Von Mises stress at the surface of the defect as a function of the increase in pressure with parabolic default $(\mathrm{c}=25 \mathrm{~mm}, \mathrm{~d}=2 \mathrm{~mm})$

A mesh sensitivity study was conducted to choose the appropriate mesh size (see Fig. 3a). The stress-number of elements curve allows us to choose the size of the elements. In the case of the parabolic HDPE pipe, we have chosen a size of 1.3 $10^{-2} \mathrm{~m}$ which corresponds to 28,443 nodes and 14,911 elements. In the vicinity of the defect, the mesh has been further refined for better results. A sphere of radius $0.1 \mathrm{~m}$ was located at the level of the defect with a size of 5.5 to $10^{-3} \mathrm{~m}$ of the elements (see Fig. 3b). Then, the analysis was conducted considering different levels of pressure. 


\section{NUMERICAL RESULTS}

o obtain the results, the pressure is increased until the Von Mises stress is close to the tensile strength of the material which is $27.62 \mathrm{MPa}$ [22]. The values of the depth and the length of the defect are varied, and the value of the pressure is recorded each time.

The numerical simulation was carried out in the same way for the other superficial defects. The resulting pressures after simulation are shown in Tab. 2.

\begin{tabular}{cccccccc}
\hline$a(\mathrm{~mm})$ & $\mathrm{a} / \mathrm{e}$ & $c(\mathrm{~mm})$ & Burst pressure $(\mathrm{MPa})$ & $\begin{array}{c}\text { Crack initiation } \\
\text { pressure }(\mathrm{MPa}) \\
\text { Formula (ref. 19) }\end{array}$ & $\begin{array}{c}\text { Numerical crack } \\
\text { initiation Pressure } \\
(\mathrm{MPa})\end{array}$ & $\Delta 1(\%)$ & $\Delta 2(\%)$ \\
2 & 0.167 & 25 & {$[5.36 ; 5.11]$} & 3.9 & 3.555 & 4.858 & 33.71 \\
4 & 0.333 & 34.87 & {$[4.58 ; 4.84 ; 4.81]$} & 3.417 & 3.220 & 6.740 & 38.50 \\
6 & 0.5 & 42.14 & {$[4.25 ; 4.03 ; 4.1]$} & 2.8 & 2.300 & 10.34 & 49.47 \\
8 & 0.667 & 48 & {$[3.52 ; 3.59 ; 3.58]$} & 2.4 & 1.843 & 19.75 & 54.93 \\
10 & 0.833 & 52.91 & {$[3.11]$} & 2.167 & 1.470 & 28.01 & 52.75 \\
\hline
\end{tabular}

Table 2: Burst pressure vs crack initiation pressure.

$\Delta_{1}$ : Offset between the value of the burst pressure determined by the formula (ref.19) and that calculated by finite elements.

$\Delta_{2}$ : Offset between the crack initiation pressure and the burst pressure.

The values given by the formula are in good agreement with the values of the starting pressure calculated numerically with an error $\Delta_{1}$ which does not exceed $23 \%$ and an average error of $16 \%$. The crack initiation pressures are lower than the burst pressures with an offset $\Delta_{2}$ varying between $32 \%$ and $52 \%$. The numerically determined crack initiation pressures and those given by the proposed formula as well as the experimentally determined burst pressures are shown in Fig. 5 .

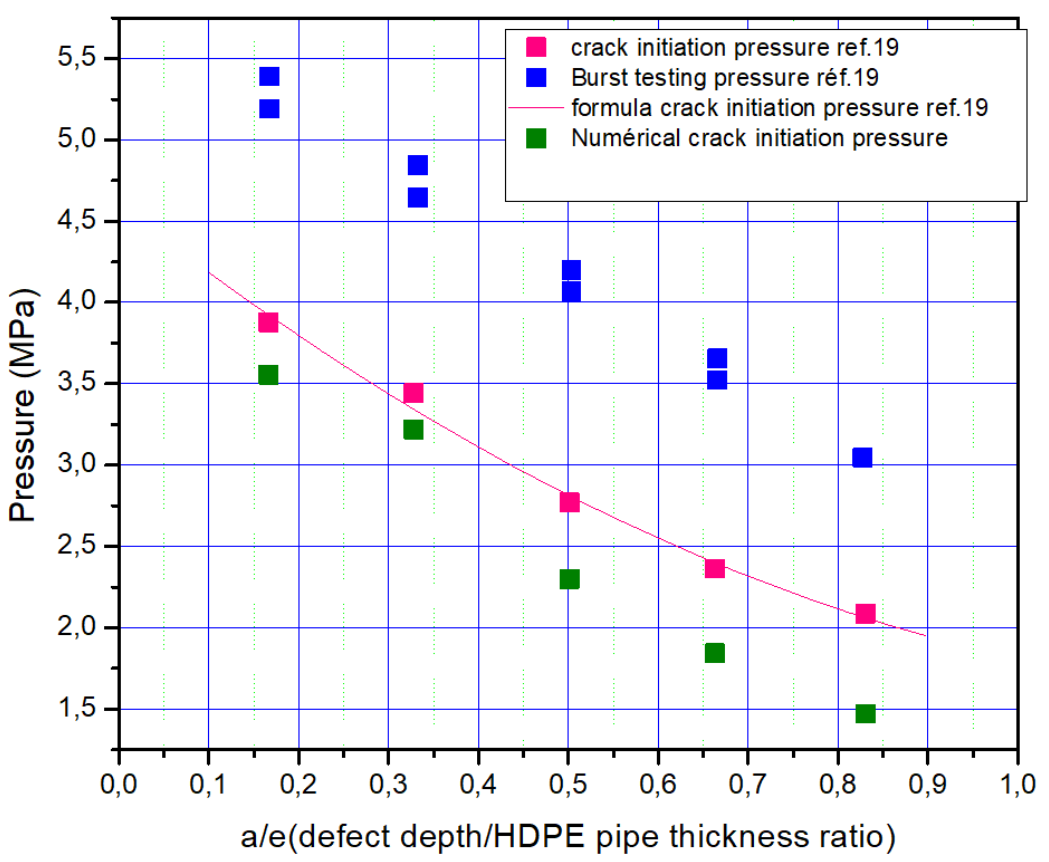

Figure 5: Comparison between burst pressures and initiation crack pressures.

The initiation crack pressure is the minimum loading level involving the initiation of the crack. The initiation crack pressure depends on the one hand on the mechanical characteristics of the material, and on the other hand it is related to the geometric parameters (geometry of the pipe and the size of the defect). Fig. 5 shows that the numerically calculated initiation crack pressure are in agreement with the pressure values given by the formula proposed in [19] the initiation 
crack pressures are lower than the burst pressures with a variable offset. This offset comes from the crack propagation phase. In fact, the initiation of the crack is followed by a phase of propagation of the crack on the remaining ligament until complete bursting.

\section{New bybrid composite repair system}

Repair with composite materials can be an effective leak containment solution to repair defects that can cause leaks in potable water supply pipes due to future deterioration such as corrosion and erosion. Benefits associated with composite repair systems include short length of time needed to complete a repair, undisrupted product transmission in the piping system while the repair is made and eliminating the possibility of welding or cutting of the pipeline is required. Industry analysis shows composite repair systems are, on average, $73 \%$ cheaper than replacing the damaged section completely [23]. For the reinforcement of the corroded HDPE 100 pipe with a surface defect, and in order to give it the mechanical characteristics of a healthy and flawless tube, we used the new hybrid composite. In order to achieve this, we used the Ansys Workbench 2020 R1 code to create the layers of composite that will be used to repair the defective tube.

The new hybrid composite $\left(90 / 45_{2} / 0\right)$ consists of two layers of perlon, two layers of glass fiber and ten grams of granulated of dates. The mechanical characteristics of the new hybrid composite are presented in the table below [24].

\begin{tabular}{cccccc}
\hline $\begin{array}{c}\text { Yield } \\
\text { Strength (MPa) }\end{array}$ & $\begin{array}{c}\text { Ultimate tensile } \\
\text { Strength (MPa) }\end{array}$ & $\begin{array}{c}\text { Young } \\
\text { modulus } \\
(\mathrm{MPa})\end{array}$ & $\begin{array}{c}\text { Elongation } \\
\mathrm{A} \%\end{array}$ & $\begin{array}{c}\text { Normal bending } \\
\text { stress (MPa) }\end{array}$ & $\begin{array}{c}\text { Maximum interlaminar } \\
\text { shear stress (MPa) }\end{array}$ \\
29.628 & 31.63 & 10.829 & 3.94 & 42.1 & 1.26 \\
\hline
\end{tabular}

Table 3: The mechanical characteristics of the new hybrid composite.

The Von Mises stress in the vicinity of the defect was compared for HDPE 100 tube without and with composite repair. The new hybrid composite layer with a thickness $1.2 \mathrm{~mm}$ was utilized (see Fig. 6). The contact between composite and pipe surfaces is assumed to be perfectly bonded.
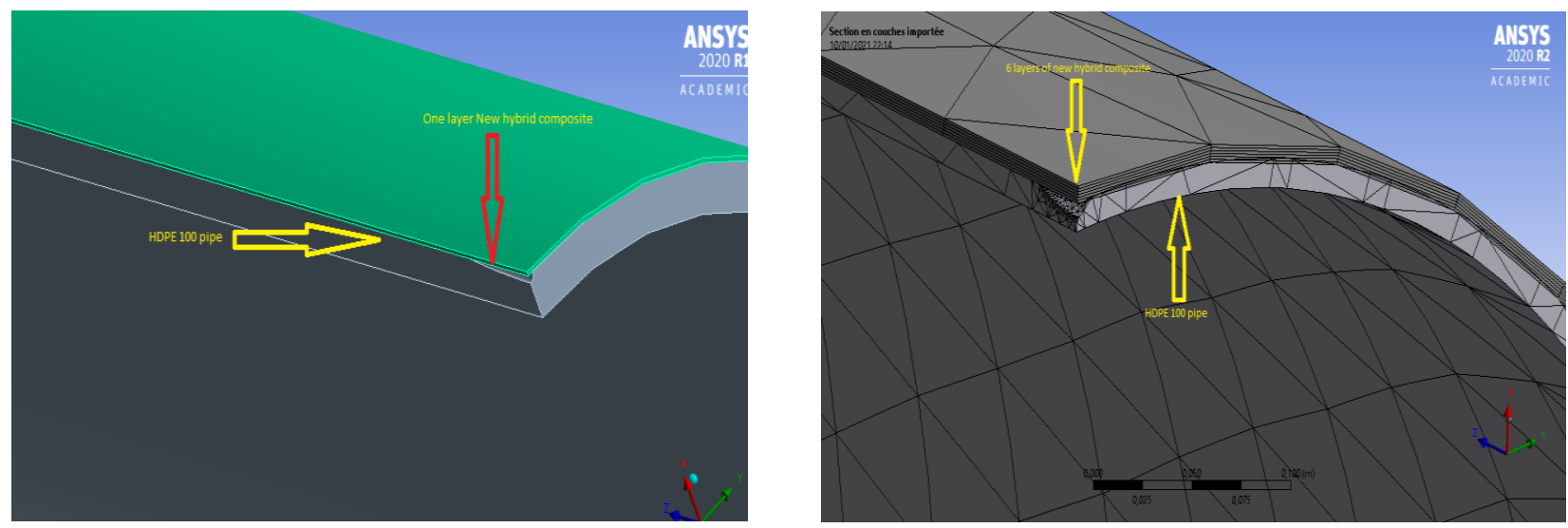

Figure 6: Corroded HDPE 100 pipe reinforced with the new hybrid composite.

The results obtained after simulation show that the Von Mises stress of the structure is modified when the HDPE 100 pipe with a (parabolic) defect is repaired by the new hybrid composite (Tab.4).

It can be seen from the results of Tab. 4 that:

$\checkmark$ The maximum von Mises stress decreases when the HDPE 100 pipe is repaired using the hybrid composite.

$\checkmark$ The hybrid composite, if its thickness is increased or the number of its layers is multiplied can restore the tube to the mechanical characteristics of a healthy tube. 
These results show that the new hybrid composite can be used in the rehabilitation and repair of HDPE pipes used for the transport of drinking water.

The acceptance of composite materials as an alternative to conventional repair materials is indicated through the recent development of several codes and standards [25]. The standards recognize composites as a legitimate repair material. Long-term performance is a main concern for composite repair system.

\begin{tabular}{|c|c|c|c|c|c|c|c|c|c|}
\hline & Defect & & & & Maximum & $\begin{array}{l}\text { value of Von } 1 \\
(\mathrm{MPa})\end{array}$ & lises stress & & \\
\hline$a(\mathrm{~mm})$ & $\mathrm{a} / \mathrm{e}$ & $c(\mathrm{~mm})$ & $\begin{array}{l}\text { Pipe non } \\
\text { repaired }\end{array}$ & $\begin{array}{c}\text { Pipe repaired } \\
\text { by } \\
\text { One layer }\end{array}$ & $\begin{array}{c}\text { Pipe repaired } \\
\text { by } \\
\text { two layers }\end{array}$ & $\begin{array}{c}\text { Pipe repaired } \\
\text { by } \\
\text { three layers }\end{array}$ & $\begin{array}{c}\text { Pipe repaired } \\
\text { by } \\
\text { four layers }\end{array}$ & $\begin{array}{c}\text { Pipe } \\
\text { Repaired } \\
\text { by } \\
\text { five layers }\end{array}$ & $\begin{array}{c}\text { Pipe } \\
\text { Repaired } \\
\text { by } \\
\text { six layers }\end{array}$ \\
\hline 2 & 0.167 & 25 & 14.39 & 13.11 & 11.94 & 10.88 & 9.91 & 9.03 & 8.22 \\
\hline 4 & 0.333 & 34.87 & 18.68 & 18.31 & 17.94 & 17.59 & 17.24 & 16.90 & 16.56 \\
\hline 6 & 0.5 & 42.14 & 22.374 & 21.913 & 21.46 & 21.01 & 20.58 & 20.16 & 19.74 \\
\hline 8 & 0.667 & 48 & 24.377 & 23.015 & 21.72 & 20.51 & 19.36 & 18.28 & 17.26 \\
\hline 10 & 0.833 & 52.91 & 25.667 & 24.893 & 24.14 & 23.411 & 22.70 & 22.02 & 21.33 \\
\hline
\end{tabular}

Table 4: HDPE 100 Pipe repaired with new hybrid composite.

\section{CONCLUSION}

$\mathrm{H}$

DPE 100 pipes for the transport of drinking water are subject to corrosion failure resulting in surface defects that weaken the pipe. This study focuses on the assessment of HDPE 100 pipes in the presence of surface defects as well as a proposal of a composite reinforcement using a new hybrid composite material. For this purpose, a numerical model validated with experimental data is developed in ANSYS. The results of the numerical analysis showed that the presence of defects may increase significantly the level of stress near the crack tip (stress concentration zone). A propagation of this anomaly would generate the ruin of the structure which will lead to a downtime of the network and require repairs. The numerical results of the reinforcement based on the new hybrid composite material showed that the Von Mises stress decreases when the tube is reinforced with a composite layer as preventive measure (before ruin). A parametric study showed that the Von Mises equivalent stress increases with increasing defect length and depth. The repair by this system of new hybrid composite, which has the qualities of being economical and non-polluting, can be very effective in practice because it helps to restore corroded HDPE pipe to its initial service pressure. Long-term performance is a main concern for composite repair system. In response to that, a large research program sponsored by PTI Polymer Transformation Innovation is conducted to better understand the long-term performance of composite repair systems using this new hybrid composite.

\section{REFERENCES}

[1] Rubeiz, C. (2010). Impact of Potable Water Disinfectants on PE Pipe, Technical Report: Jana Laboratories Inc., pp.134

[2] Khelif, R. (2007). Analyse de la rupture et évaluation de la durée de vie basée sur la fiabilité des tubes en polyéthylène pour le transport du gaz, (Doctoral dissertation, Université Blaise Pascal-Clermont-Ferrand II).

[3] Krishnaswamy, R. K. (2005). Analysis of ductile and brittle failures from creep rupture testing of high-density polyethylene (HDPE) pipes, Polymer, 46(25), pp. 11664-11672.

[4] Guide d'étude des Réseaux en Polyéthylène. (2012).2011th-2012th ed. Association pluridisciplinaire Réso-PE.

[5] Gabriel, L. H., \& Bennett, O. (2010). The complete corrugated polyethylene pipe design manual and installation guide. Plastics Pipe Institute (PPI).

[6] History of HDPE and HDPE pipe products, PE Specialisten Technology, pp. 1-2. 
[7] Ziegler, K. (1965). Consequences and development of an invention. Rubber Chemistry and Technology, 38(1), pp. 23-36.

[8] Brömstrup, H. (Ed.). (2004). PE 100 pipe systems. Vulkan-Verlag GmbH.

[9] Addiego, F. (2006). Caractérisation de la variation volumique du polyéthylène au cours de la déformation plastique en traction et en fluage (Doctoral dissertation, Institut National Polytechnique de Lorraine).

[10] Guidara, M. A. (2016). Analyse des conditions de rupture des conduites d'adduction d'eau potable en polyéthylène, sous l'effet d'écoulement transitoire, en présence d'un défaut, (Doctoral dissertation, Université de Lorraine; Université de Sfax (Tunisie)).

[11] Arieby, R. (2007). Caractérisation mécanique et modélisation thermodynamique du comportement anisotrope du polyéthylène à haute densité. Intégration des effets d'endommagement, (Doctoral dissertation, Institut National Polytechnique de Lorraine).

[12] Ferhoum, R. (2012). Etude expérimentale et modélisation numérique du comportement du PEHD à l'état vierge et après vieillissement thermique, (Doctoral dissertation, Université Mouloud Mammeri).

[13] Cazenave, J. (2005). Sur le compromis rigidité/durabilité du Polyéthylène Haute Densité en relation avec la structure de chaîne, la microstructure et la topologie moléculaire issues de la cristallisation, (Doctoral dissertation, Lyon, INSA).

[14] Peterlin, A. (1971). Molecular model of drawing polyethylene and polypropylene, Journal of materials science, 6(6), pp. 490-508. DOI: 10.1007/BF00550305

[15]Zhang, C., \& Moore, I. D. (1997). Nonlinear mechanical response of high-density polyethylene. Part I: Experimental investigation and model evaluation, Polymer Engineering \& Science, 37(2), pp. 404-413. DOI: 10.1002/pen.11683.

[16]Zhang, C., \& Moore, I. D. (1997). Nonlinear mechanical response of high-density polyethylene. Part II: Uniaxial constitutive modeling, Polymer Engineering \& Science, 37(2), pp. 414-420. DOI: 10.1002/pen.11684

[17] Ouardi, A., Majid, F., Mouhib, N., \& Elghorba, M. (2018). Residual life prediction of defected Polypropylene Random copolymer pipes (PPR), Frattura ed Integrità Strutturale, 12(43), pp. 97-105. DOI: 10.3221/IGF-ESIS.43.07

[18] Majid, F., Nattaj, J., Elghorba, M. (2016).Pressure vessels design methods using the codes, fracture mechanics and multiaxial fatigue, Frattura ed Integrità Strutturale, 38, pp. 273-280. DOI: 10.3221/IGF-ESIS.38.37.

[19] Bouaziz, M. A. (2016). Sécurité des réseaux d'adduction d'eau potable en présence de défaut superficiel sous l'effet du phénomène de coup de bélier, (Doctoral dissertation, Université de Lorraine; Université de Sfax (Tunisie)).

[20] H. Berrekia, D. Benzerga, A. Haddi, (2019). Behavior and damage of a pipe in the presence of a corrosion defect depth of $10 \%$ of its thickness and highlighting the weaknesses of the ASME/B31G, Frattura ed Integrità Strutturale,49, pp. 643-654; DOI: 10.3221/IGF-ESIS.49.58

[21] Benzerga, D. (2015).Burst pressure estimation of corroded pipeline using damage mechanics, Mmssd, ISBN 978-3319-14531-0. DOI: 10. 1007/978-3-319-14532-7 springer.

[22] Chouiter, A., Benzerga, D., Haddi, A. and Tamine, T. (2019).Prediction of cycle life of expansion bellows for fixed tube sheet heat exchanger, Frattura ed Integrità Strutturale, 47 30-38; DOI: 10.3221/IGF-ESIS.47.03

[23] Lim, K. S., Siti Nur Afifah, A., Norhazilan, M. N., \& Nordin, Y. (2016). Systems for repair and rehabilitation of corroded oil \& gas pipelines, Jurutera 13

[24] K. Tadjine. (2007). Contribution à l'étude et à l'amélioration du comportement mécanique des matériaux composites stratifiés à usage biomécanique, (thèse de doctorat. Université d'Artois).

[25] Repair of Pressure Equipment and Piping, (2011). The American Society of Mechanical Engineers, ASME PCC-22011. 